\title{
Article \\ Tracking Reservoirs of Antimicrobial Resistance Genes in a Complex Microbial Community Using Metagenomic Hi-C: The Case of Bovine Digital Dermatitis
}

\author{
Ashenafi F. Beyi ${ }^{1}\left(\mathbb{D}\right.$, Alan Hassall ${ }^{2}$, Gregory J. Phillips ${ }^{1}\left(\mathbb{D}\right.$ and Paul J. Plummer ${ }^{1,2,3, * \mathbb{C}}$ \\ 1 Veterinary Microbiology and Preventive Medicine, Iowa State University, Ames, IA 50011, USA; \\ afbeyi@iastate.edu (A.F.B.); gregory@iastate.edu (G.J.P.) \\ 2 Veterinary Diagnostic and Production Animal Medicine, Iowa State University, Ames, IA 50011, USA; \\ ahassall@iastate.edu \\ 3 National Institute of Antimicrobial Resistance Research and Education, Ames, IA 50010, USA \\ * Correspondence: pplummer@iastate.edu
}

\section{check for}

updates

Citation: Beyi, A.F.; Hassall, A.; Phillips, G.J.; Plummer, P.J. Tracking Reservoirs of Antimicrobial Resistance Genes in a Complex Microbial Community Using Metagenomic Hi-C: The Case of Bovine Digital Dermatitis. Antibiotics 2021, 10, 221. https://doi.org/ 10.3390 /antibiotics 10020221

Academic Editor: Mohammad Amjad Kamal

Received: 22 January 2021

Accepted: 19 February 2021

Published: 23 February 2021

Publisher's Note: MDPI stays neutral with regard to jurisdictional claims in published maps and institutional affiliations.

Copyright: (c) 2021 by the authors. Licensee MDPI, Basel, Switzerland. This article is an open access article distributed under the terms and conditions of the Creative Commons Attribution (CC BY) license (https:/ / creativecommons.org/licenses/by/ $4.0 /)$.

\begin{abstract}
Bovine digital dermatitis (DD) is a contagious infectious cause of lameness in cattle with unknown definitive etiologies. Many of the bacterial species detected in metagenomic analyses of DD lesions are difficult to culture, and their antimicrobial resistance status is largely unknown. Recently, a novel proximity ligation-guided metagenomic approach (Hi-C ProxiMeta) has been used to identify bacterial reservoirs of antimicrobial resistance genes (ARGs) directly from microbial communities, without the need to culture individual bacteria. The objective of this study was to track tetracycline resistance determinants in bacteria involved in DD pathogenesis using Hi-C. A pooled sample of macerated tissues from clinical DD lesions was used for this purpose. Metagenome deconvolution using ProxiMeta resulted in the creation of 40 metagenome-assembled genomes with $\geq 80 \%$ complete genomes, classified into five phyla. Further, 1959 tetracycline resistance genes and ARGs conferring resistance to aminoglycoside, beta-lactams, sulfonamide, phenicol, lincosamide, and erythromycin were identified along with their bacterial hosts. In conclusion, the widespread distribution of genes conferring resistance against tetracycline and other antimicrobials in bacteria of DD lesions is reported for the first time. Use of proximity ligation to identify microorganisms hosting specific ARGs holds promise for tracking ARGs transmission in complex microbial communities.
\end{abstract}

Keywords: antimicrobial resistance genes; digital dermatitis; Hi-C ProxiMeta; resistomes; tetracycline resistance

\section{Introduction}

Bovine digital dermatitis (DD) is a contagious polymicrobial complex disease that causes lameness and is the second most significant health problem, after mastitis, on dairy farms. Its effects include reduction of milk production, loss of fertility, premature culling, deterioration of animal welfare, and increased treatment expenses [1-3]. DD is widely distributed across the world in dairy cattle, but it has also been recognized in beef cattle, sheep, and other ruminants [4-6].

High prevalence rates of DD have been reported from various countries. For instance, $34 \%$ in Canadian dairy cattle [7]; $38 \%$ to $41 \%$ in French dairy cows [2]; $21.2 \%$ in Dutch dairy cattle [8]; 32.2\% in dairy cows and 10.8\% in beef cows of Victoria, Australia [9]; and $0.5 \%$ to $21 \%$ in beef cattle in the United Kingdom [4]. Prevalence rates ranging from $31 \%$ to $89 \%$ (with monthly within-herd morbidity rates ranging from $0.5 \%$ to $12 \%$ ) were reported in southern California dairy herds in the 1990s [10]. Furthermore, DD can occur in outbreaks on dairy farms. In South Africa, $72 \%$ of lactating cows in a dairy herd were affected with recurrence after seven months, infecting $37 \%$ of the lactating herd, of which $48 \%$ represented new cases [11]. Moreover, DD results in substantial direct and indirect economic losses on dairy farms. Relun and colleagues [2] conducted a six-month follow-up 
study on French dairy farms, wherein they reported 0.50 to $0.70 \mathrm{~kg} /$ day less milk yield in a DD cow compared to the healthy cow. The predicted average cost of lameness per individual cow attributed to DD was 133 USD per case [12].

DD is a multifactorial disease of cattle. Factors related to the environment, management, and individual animals play a combined role in its pathogenesis, with the leading players being infectious agents [13]. The exact etiologic agents of DD are yet to be determined; however, several bacterial species have been detected in the lesions $[5,14,15]$, which earned it the name "polymicrobial infectious disease" [5]. While there is insufficient evidence to suggest the involvement of viruses and fungi in its pathogenesis, bacteria are substantiated as the leading infectious causes of this disease on the basis of the effectiveness of antibiotic treatment and the detection of bacteria in the DD lesions $[5,16,17]$.

While different bacterial species are implicated in DD, critical microorganisms include Spirochaetes, particularly the genera Treponema, Mycoplasma, Fusobacterium, Porphyromonas, Bacteroides, Campylobacter, and Borrelia, as well as Dichelobacter nodosus and Candidatus Aemobophilus asiaticus $[15,18,19]$. Spirochetes, such as Treponema medium, Treponema denticola, and Treponema phagedenis, are predominant in active lesions compared to other bacteria $[14,20-26]$. Moreover, studies show that the types and abundances of bacteria involved vary with the stage of the lesions. This suggests that various bacterial species have distinct roles at different stages of the disease, as well as reinforcing the polybacterial nature of DD $[14,26,27]$. Cultivation of many of these bacterial species in vitro remains a significant challenge.

Control strategies for DD include local or systemic antibiotic or antiseptic solutions for clinical cases, surgical removal of horny proliferation in the case of highly proliferative lesions, foot baths that contain formalin or heavy metals such as copper sulfate and zinc sulfate, and good hygienic and biosecurity measures on farms [13]. Topical applications of oxytetracycline on lesions are commonly used to treat individual cows suffering from DD. This treatment has been reported to yield positive responses [11,28,29]. However, anecdotal reports of clinical resistance exist that suggest the emergence of antimicrobial resistance among causative agents of DD [10,30,31].

Tetracyclines are relatively safe and low-cost drugs that are widely used broadspectrum antimicrobial agents with activity against a broad range of bacteria, including anaerobic and aerobic Gram-positive and Gram-negative species, along with cell wall-free mycoplasmas and other bacteria [32]. Resistance to tetracyclines continues to rise globally, which was first reported in 1953 in Shigella dysenteriae isolates [32]. Recently, dairy producers have been challenged by restrictions on the use of medically important antibiotics in food-producing animals, which are aimed at mitigating the development of antimicrobial resistance in humans [33], as well as recurrence of DD cases. T. phagedenis isolates from cows with DD lesions have demonstrated intermediate minimum inhibitory concentration (MIC) values for oxytetracycline [31,34]. In a previous study, antimicrobial resistance genes (ARGs) conferring resistance to copper and zinc were reported in DD cases, but oxytetracycline resistance determinants were not detected [19]. To our knowledge, there are no published works on tetracycline resistance in DD except for the MIC study conducted by Yano et al. [31], and several of the available methods are incapable of identifying ARGs in non-cultivable etiologic agents.

Cultivation-independent metagenomics of environmental samples, such as wholegenome shotgun sequencing, has been used to discover ARGs in complex environments [35]. However, the method is incapable of definitively identifying the bacterial reservoirs associated with specific ARGs. Proximity ligation methods such as $\mathrm{Hi}-\mathrm{C}$ and $3 \mathrm{C}$ have been developed to detect interactions between DNA molecules originating in the same cell, including within microbial communities [36-39]. As a result, these methods can reconstruct metagenome-assembled genomes (MAGs) from bacterial communities such as those of the mammalian gut communities $[37,40]$. This method has also been used to identify bacterial taxa hosting specific ARGs and provided comprehensive information about the resistome in the sample [36,40]. Moreover, identification of the reservoirs of ARGs carried by mobile genetic elements is difficult using the conventional metagenomic methods; however, the 
proximity ligation employed during the metagenomic Hi-C library preparation has made it possible to identify the hosts of such resistance genes. This novel method involves linking non-chromosomal DNA to the chromosome while the bacterial cell is still intact, which enables tracking the sources of the mobile genetic elements. Thus, the advantage of this method over other metagenomic approaches is that, besides detecting resistome in complex environmental samples, it can identify the bacterial host carrying the target resistance genes [40]. Given the power of this sequencing method to link specific genotypes to their taxonomic source, the objective of this study was to track bacterial reservoirs of ARGs conferring resistance to tetracyclines and other antibiotics in DD lesions using the metagenomic $\mathrm{Hi}-\mathrm{C}$ method. The Hi-C approach holds promise for tracking the horizontal transfer of ARGs to other pathogens in complex microbial communities and their dissemination in the environments, including on animal farms.

\section{Results}

In this study, DD lesion samples from various disease stages were combined to capture an overall picture of antimicrobial resistance in DD. This mixture was used as an input to the ProxiMeta metagenomic Hi-C method to first reconstruct genomes of DD community members and then to examine the resistome profile of each such genome.

\subsection{Microbiome Profiles}

Metagenome deconvolution using ProxiMeta resulted in the creation of 308 putative genome and genome fragment clusters, with genome size ranging from 234,157 to 2,957,833 base pairs. However, only 40 of the clusters had $\geq 80 \%$ complete genome (Table S1), $15.26 \%$ of the 308 clusters. These clusters were classified into five bacterial phyla (Table 1), namely, Bacteroidetes (relative abundance 5.27\%), Spirochaetes (4.87\%), Firmicutes (3.83\%), Tenericutes (0.84), and Proteobacteria $(0.45 \%)$. Moreover, some bacterial taxa were identified at the species level, including Porphyromonas levii (1.04\%), Treponema phagedenis (1.0\%), Mycoplasma fermentans $(0.63 \%)$, T. medium $(0.51 \%)$, Porphyromonas somerae $(0.36 \%)$, and Streptococcus henryi (0.25\%).

Table 1. Relative abundances of bacterial taxa with $\geq 80 \%$ complete genome identified in digital dermatitis lesions. These bacterial taxa account for $15.26 \%$ of the total bacterial taxa detected in the sample.

\begin{tabular}{cccc}
\hline Phyla & Lowest Level Identification & Classification & Relative Abundance (\%) \\
\hline Bacteroidetes & & Phylum & 5.27 \\
& Porphyromonas somerae & Species & 0.36 \\
& Porphyromonas levii & Species & 1.04 \\
& Porphyromonadaceae (unclassified) & Family & 0.88 \\
Spirochaetes & Bacteroidetes (unclassified) & Phylum & 2.99 \\
& & Phylum & 4.87 \\
& Treponema phagedenis & Species & 1.00 \\
Firmicutes & Treponema medium & Species & 0.51 \\
& Spirochaetaceae (unclassified) & Family & 3.36 \\
& Phylum & 3.83 \\
Tenericutes & Streptococcus henryi & Species & 0.25 \\
& Lactobacillales (unclassified) & Order & 1.15 \\
Proteobacteria & Clostridiales (unclassified) & Order & 2.43 \\
& Phylum & Species & 0.84 \\
& Mycoplasma fermentans & Genus & 0.63 \\
& Mycoplasma (unclassified) & Phylum & 0.21 \\
& Betaproteobacteria (unclassified) & Class & 0.45 \\
\hline
\end{tabular}

Out of the 40 clusters, 27 of them had an assembled 16S ribosomal RNA (rRNA) sequence with gene length ranging from 368 to 1555 base pairs. These $16 \mathrm{~S}$ rRNA sequences 
were used to classify each such cluster more specifically. A best match organism, percent identity, and gene size of these bacterial clusters using 16S rRNA sequence BLAST (Basic Local Alignment Search Tool) are presented in Table 2. For instance, cluster 5 Spirochaetaceae had a $97.23 \%$ match with Treponema refringens, cluster 18 (Spirochaetaceae) a $99.01 \%$ match with Treponema species, cluster 13 (Bacteroidetes) an $89.96 \%$ match with P. somerae, and cluster 26 (Porphyromonadaceae) a $94.48 \%$ match with P. levii. More interestingly, six clusters only identified as kingdom Bacteria were further classified as Spirochaetes species (cluster 14), P. levii (cluster 25), Acholeplasmatales species (cluster 29), Erysipelothrix rhusiopathiae (cluster 32), Bacteroidetes species (cluster 36), and Tenericutes species (cluster 38).

Table 2. Best match bacterial species, percent identity, and gene sizes of 27 bacterial clusters using $16 \mathrm{~S}$ ribosomal RNA sequence blasting on the National Center for Biotechnology Information (NCBI) website.

\begin{tabular}{|c|c|c|c|c|}
\hline Cluster-ID & Top References & Best Match & Identity (\%) & 16S rRNA Length (Bases) \\
\hline cluster_3 & p_Bacteroidetes & Uncultured bacterium clone gls269 & 84.42 & 1511 \\
\hline cluster_4 & Porphyromonas_somerae_DSM_23386 & $\begin{array}{l}\text { Porphyromonas somerae DSM } 23386 \text { strain } \\
\text { JCM } 13867\end{array}$ & 98.35 & 567 \\
\hline cluster_5 & f_Spirochaetaceae & Treponemarefringens & 97.23 & 1365 \\
\hline cluster_6 & p_Bacteroidetes & $\begin{array}{c}\text { Bacteroidia bacterium feline oral taxon } 312 \\
\text { clone UI046 }\end{array}$ & 93.38 & 707 \\
\hline cluster_8 & c_Betaproteobacteria & Oligella ureolytica DSM 18253 & 96.51 & 1540 \\
\hline cluster_12 & o_Clostridiales & $\begin{array}{c}\text { Ezakiella sp. Marseille-P2951 strain } \\
\text { Marseille-P2951T }\end{array}$ & 99.73 & 747 \\
\hline cluster_13 & p_Bacteroidetes & $\begin{array}{c}\text { Porphyromonas somerae DSM } 23386 \text { strain } \\
\text { JCM } 13867\end{array}$ & 89.96 & 1113 \\
\hline cluster_14 & k_Bacteria & Spirochaeta sp. canine oral taxon 314 clone $1 \mathrm{~A} 090$ & 99.92 & 1234 \\
\hline cluster_16 & p_Bacteroidetes & $\begin{array}{c}\text { Bacteroidia bacterium feline oral taxon } 312 \\
\text { clone UI046 }\end{array}$ & 85.81 & 721 \\
\hline cluster_17 & o_Clostridiales & Catonella sp. oral clone BR063 & 94.1 & 874 \\
\hline cluster_18 & f_Spirochaetaceae & Treponema sp. canine oral taxon 233 clone QB043 & 99.01 & 414 \\
\hline cluster_19 & Porphyromonas_levii_DSM_23370 & Porphyromonas levii strain Israel & 99.4 & 368 \\
\hline cluster_21 & o_Clostridiales & Uncultured rumen bacterium & 98.4 & 566 \\
\hline cluster_23 & Streptococcus_henryi_DSM_19005 & Streptococcus henryi strain OZK31 & 98.45 & 916 \\
\hline cluster_24 & g_Mycoplasma & Mycoplasma agalactiae 5632 & 93.52 & 802 \\
\hline cluster_25 & k_Bacteria & Porphyromonas levii DSM 23370 strain JCM 13866 & 94.59 & 398 \\
\hline cluster_26 & f_Porphyromonadaceae & Porphyromonas levii DSM 23370 strain JCM 13866 & 94.48 & 372 \\
\hline cluster_27 & Mycoplasma_fermentans_JER & Mycoplasma fermentans M64 & 99.87 & 1522 \\
\hline cluster_29 & k_Bacteria & $\begin{array}{c}\text { Acholeplasmatales bacterium canine oral taxon } 172 \\
\text { clone QC046 }\end{array}$ & 98.6 & 1555 \\
\hline cluster_30 & c_Gammaproteobacteria & Pseudomonas sp. M-08 gene & 97.87 & 1324 \\
\hline cluster_31 & o_Clostridiales & Uncultured bacterium clone 1101352040638 & 93.16 & 1536 \\
\hline cluster_32 & k_Bacteria & Erysipelothrix rhusiopathiae & 92.17 & 611 \\
\hline cluster_33 & o_Clostridiales & Peptoniphilaceae bacterium SIT14 & 96.86 & 1536 \\
\hline cluster_35 & o_Clostridiales & Uncultured Firmicutes bacterium clone P-07 & 99.68 & 1510 \\
\hline cluster_36 & k_Bacteria & Uncultured Bacteroidetes bacterium clone BL2_5 & 98.27 & 1536 \\
\hline cluster_38 & k_Bacteria & Uncultured Tenericutes bacterium clone P-06 & 100 & 1542 \\
\hline cluster_39 & o_Clostridiales & Clostridium sticklandii str. DSM 519 & 85.56 & 471 \\
\hline
\end{tabular}

Phylogenetic Tree

To study the genetic relatedness of Spirochaetes, Bacteroidetes, Mycoplasma, and unclassified bacterial clusters with frequently reported isolated bacterial species from DD cases, we plotted a phylogenetic tree (Figure 1). Some Spirochaetes clusters clustered with T. denticola ATCC 33520 and Treponema pedis (clusters 1, 2, 10, 15, and 28), while cluster 18 clustered around T. medium ATCC 700293 and Treponema vincentii F0403. Similarly, previously unreported Bacteroidetes and Mycoplasma genomes clustered around known and representative species, as indicated in Figure 1. 


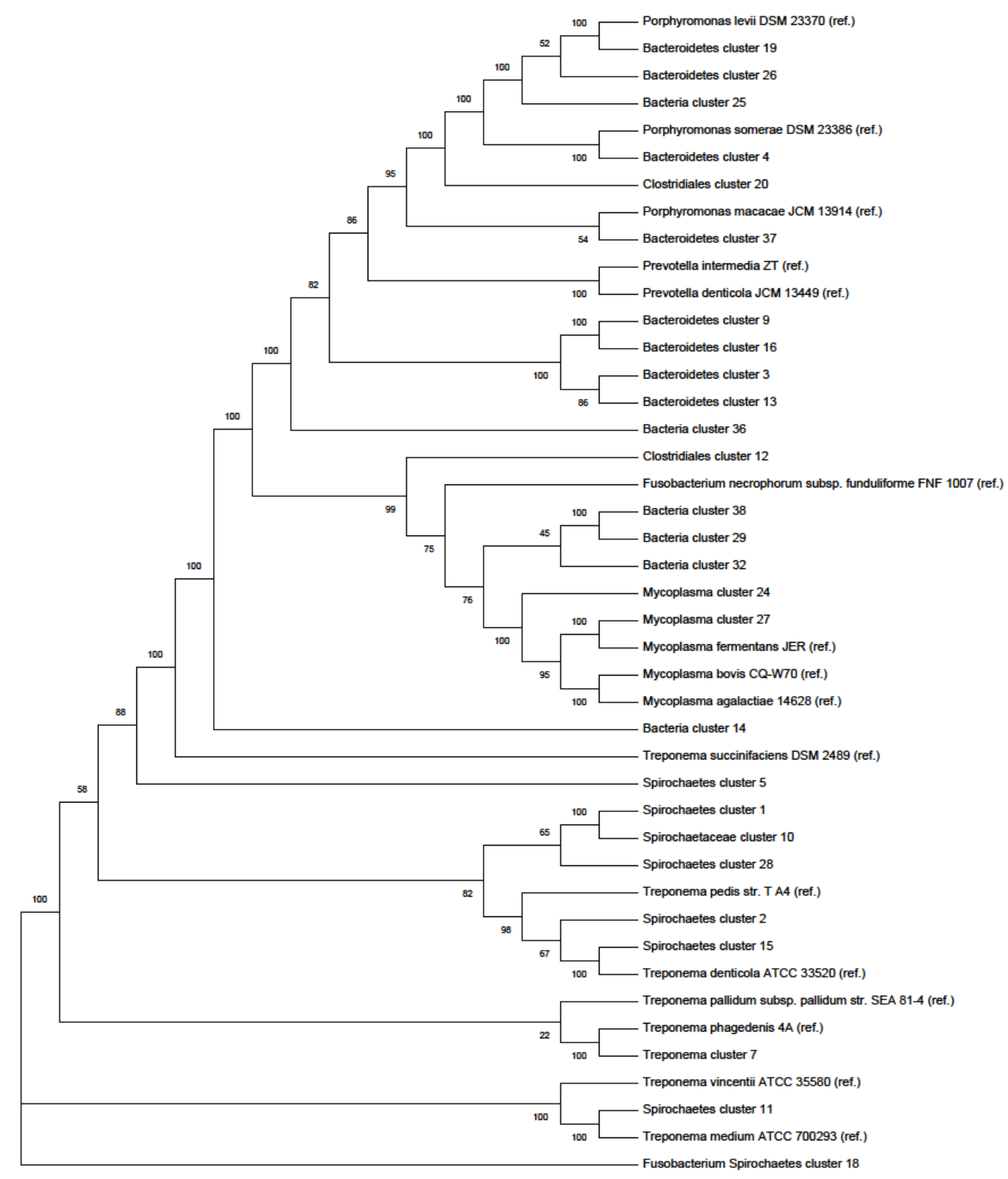

Figure 1. Phylogenetic tree of Spirochaetes, Bacteroidetes, Mycoplasma, and Bacteria from this study and reference organisms (which are labeled as "ref."). In the construction of this dendrogram, we included the sequences of selected organisms identified in the current study and previous studies as well reference organisms, and PATRIC online tool (https: / /www. patricbrc.org/app/PhylogeneticTree (accessed on 22 February 2021)) was used.

\subsection{Resistome Profiles}

Tetracycline resistance genes were identified by aligning assembled contigs to the curated resistance genes of the MEGARes database using minimap2. Hi-C data were then used to link identified resistance gene sequences to host genomes and genome fragments within ProxiMeta by counting the number of $\mathrm{Hi}-\mathrm{C}$ reads linking such sequences to putative hosts. In this study, a total of 1961 tetracycline resistance genes, grouped into 16 classes, were identified (Table 3 and Table S2). Genes encoding ribosomal protection proteins were predominant, with eight distinct classes, followed by resistance genes encoding efflux pump with six distinct classes, and one class encoding an inactivation enzyme. The most prevalent tetracycline resistance genes included tet $\mathrm{Q}(n=1265)$, tet $\mathrm{O}(n=224)$, tet $\mathrm{W}$ $(n=166)$, tet $\mathrm{M}(n=112)$, tet40 $(n=41)$, tet32 $(n=39)$, and tet $\mathrm{T}(n=32)$. Similarly, tet $\mathrm{Q}$ had the most taxonomic distribution with its presence detected in 21 of the 40 bacterial clusters 
with $\geq 80 \%$ complete genome (Figure 2), followed by tet $\mathrm{O}$ and tet $\mathrm{M}$ with each present in 11 clusters. However, some of the resistance genes, such as tet $\mathrm{B}$, tet $\mathrm{H}$, tet $\mathrm{L}$, tet 36 , and tet $\mathrm{S}$, were not identified in any of the bacterial taxa with $\geq 80 \%$ complete genomes.

Table 3. Types and distributions of tetracycline resistance genes in bacterial taxa having $\geq 80 \%$ complete genome detected in digital dermatitis lesions.

\begin{tabular}{|c|c|c|c|c|c|c|c|c|c|c|c|c|c|c|c|c|}
\hline \multirow{2}{*}{ Bacterial Taxa } & \multicolumn{6}{|c|}{ Efflux Pump } & \multicolumn{8}{|c|}{ Ribosomal Protection Proteins } & \multicolumn{2}{|r|}{ Inactivation Enzyme } \\
\hline & tet31 & tet33 & tet $\mathrm{B}$ & tet $\mathrm{H}$ & tet $\mathrm{L}$ & tet $\mathrm{Z}$ & tet32 & tet36 & tet 40 & tet $\mathrm{M}$ & tet $\mathrm{O}$ & tet $\mathrm{O}$ & tets & tet $\mathrm{T}$ & tet $\mathrm{W}$ & tet $\mathrm{X}$ \\
\hline Bacteroidetes & 0 & 0 & 0 & 0 & 0 & 1 & 0 & 0 & 1 & 3 & 3 & 435 & 0 & 0 & 2 & 0 \\
\hline Porphyromonas somerae & 0 & 0 & 0 & 0 & 0 & 0 & 0 & 0 & 0 & 2 & 0 & 19 & 0 & 0 & 0 & 0 \\
\hline Porphyromonas levii & 0 & 0 & 0 & 0 & 0 & 0 & 0 & 0 & 0 & 0 & 0 & 86 & 0 & 0 & 1 & 0 \\
\hline Porphyromonadaceae (unclass. ${ }^{*}$ ) & 0 & 0 & 0 & 0 & 0 & 0 & 0 & 0 & 1 & 1 & 1 & 68 & 0 & 0 & 0 & 0 \\
\hline Bacteroidetes (unclass.) & 0 & 0 & 0 & 0 & 0 & 1 & 0 & 0 & 0 & 0 & 2 & 262 & 0 & 0 & 1 & 0 \\
\hline Spirochaetes & 0 & 0 & 0 & 0 & 0 & 0 & 1 & 0 & 0 & 23 & 64 & 5 & 0 & 1 & 0 & 0 \\
\hline Treponema phagedenis & 0 & 0 & 0 & 0 & 0 & 0 & 0 & 0 & 0 & 2 & 63 & 1 & 0 & 0 & 0 & 0 \\
\hline Treponema medium & 0 & 0 & 0 & 0 & 0 & 0 & 0 & 0 & 0 & 14 & 0 & 0 & 0 & 0 & 0 & 0 \\
\hline Spirochaetaceae (unclass.) & 0 & 0 & 0 & 0 & 0 & 0 & 1 & 0 & 0 & 7 & 1 & 4 & 0 & 1 & 0 & 0 \\
\hline Firmicutes & 0 & 0 & 0 & 0 & 0 & 0 & 32 & 0 & 7 & 4 & 71 & 12 & 0 & 0 & 20 & 1 \\
\hline Streptococcus henryi & 0 & 0 & 0 & 0 & 0 & 0 & 0 & 0 & 0 & 1 & 0 & 0 & 0 & 0 & 1 & 0 \\
\hline Lactobacillales (unclass.) & 0 & 0 & 0 & 0 & 0 & 0 & 0 & 0 & 0 & 1 & 0 & 0 & 0 & 0 & 0 & 0 \\
\hline Clostridiales (unclass.) & 0 & 0 & 0 & 0 & 0 & 0 & 32 & 0 & 7 & 2 & 71 & 12 & 0 & 0 & 19 & 1 \\
\hline Tenericutes & 0 & 0 & 0 & 0 & 0 & 0 & 0 & 0 & 0 & 1 & 0 & 0 & 0 & 0 & 0 & 0 \\
\hline Mycoplasma fermentans & 0 & 0 & 0 & 0 & 0 & 0 & 0 & 0 & 0 & 1 & 0 & 0 & 0 & 0 & 0 & 0 \\
\hline Mycoplasma (unclass.) & 0 & 0 & 0 & 0 & 0 & 0 & 0 & 0 & 0 & 0 & 0 & 0 & 0 & 0 & 0 & 0 \\
\hline Proteobacteria & 3 & 0 & 0 & 0 & 0 & 0 & 0 & 0 & 0 & 0 & 0 & 6 & 0 & 0 & 1 & 0 \\
\hline Betaproteobacteria (unclass.) & 2 & 0 & 0 & 0 & 0 & 0 & 0 & 0 & 0 & 0 & 0 & 0 & 0 & 0 & 0 & 0 \\
\hline Gammaproteobacteria (unclass.) & 1 & 0 & 0 & 0 & 0 & 0 & 0 & 0 & 0 & 0 & 0 & 6 & 0 & 0 & 1 & 0 \\
\hline $\begin{array}{l}\text { Total Resistance Genes in the } \\
\text { Sample ( } n=308 \text { clusters) }\end{array}$ & 13 & 4 & 1 & 22 & 4 & 6 & 39 & 14 & 41 & 112 & 224 & 1265 & 15 & 32 & 166 & 3 \\
\hline
\end{tabular}

* Not further classified. ** This row provides the total numbers of antimicrobial resistance genes (ARGs) in the sample; thus, the sum of a specific ARG in bacterial clusters with $\geq 80 \%$ complete genomes does not sum up to the total number of that specific ARG or column.

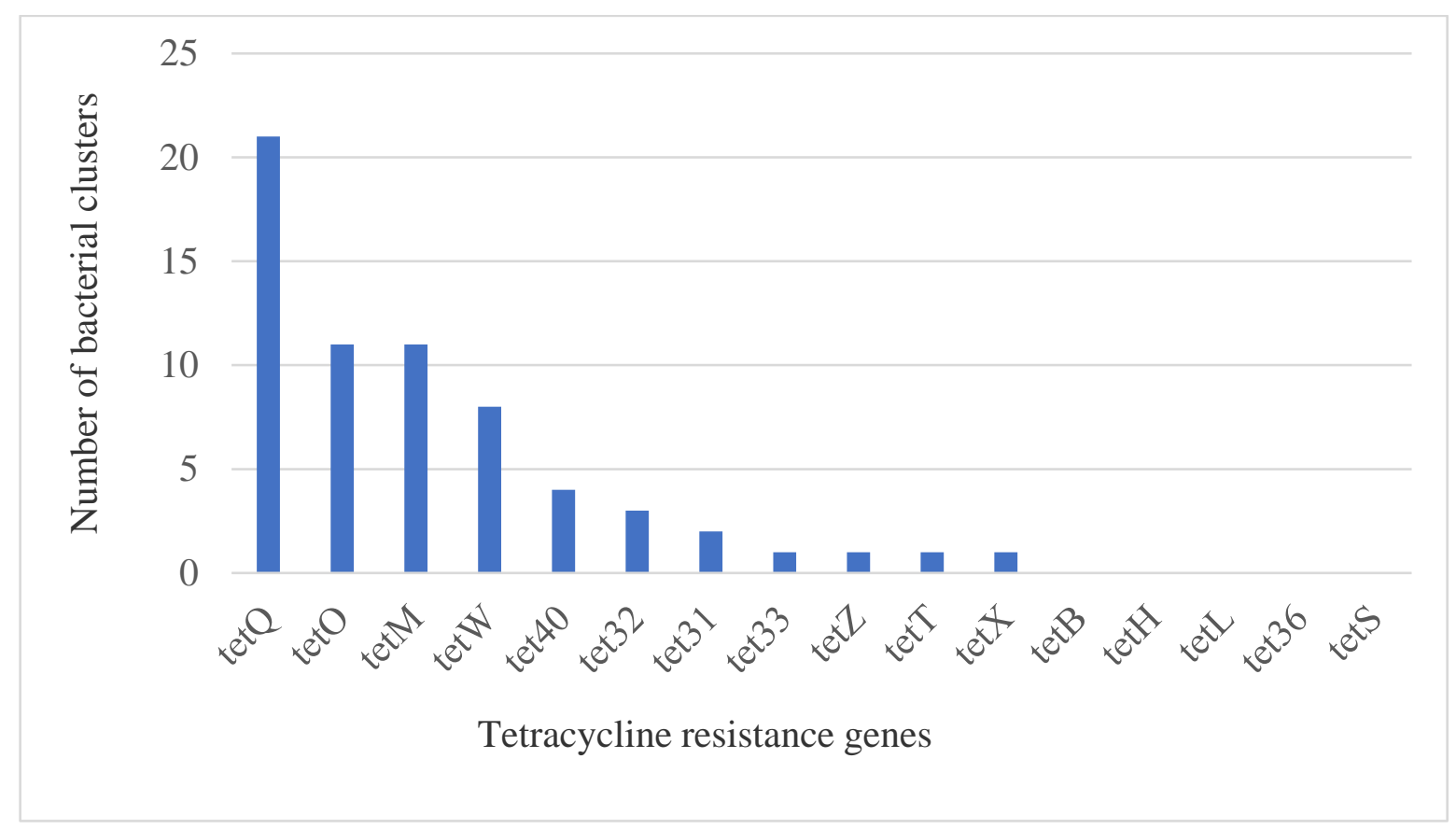

Figure 2. Numbers of bacterial clusters with $\geq 80 \%$ complete genome coverage carrying tetracycline resistance genes.

Regarding tetracycline resistance gene reservoirs, all phyla identified in the present study hosted at least one type of tetracycline resistance gene. Bacteroidetes, Firmicutes, and Spirochaetes carried the three highest abundances of resistance genes with 445, 146, and 94 hits, respectively. In terms of diversity, Firmicutes hosted seven types of tetracycline resistance genes, Bacteroidetes six, Spirochaetes five, Proteobacteria three, and Tenericutes 
one. Additionally, all phyla hosted at least one class of the ribosomal protection protein genes, while efflux pump genes were hosted only by two phyla, including Bacteroidetes and Proteobacteria. The inactivation enzyme gene was identified only in Firmicutes (family Clostridiales). Classes and numbers of the tetracycline resistance genes with their respective bacterial hosts are depicted in Table 3.

Other ARGs that co-occurred with tetracycline determinants in the microbiome of DD lesions are summarized in Table 4. Resistant determinants against aminoglycoside $(n=463)$, beta-lactams $(n=36)$, sulfonamide $(n=39)$, phenicol $(n=20)$, lincosamide $(n=153)$, and erythromycin $(n=63)$ were detected in our samples. These resistance genes showed widespread distributions in the microbial community where all phyla, except Tenericutes, hosted multiple types of the ARGs. Spirochaetes was the lead host by abundance, with a total of 85 antimicrobial determinants that encoded resistance against aminoglycoside. In contrast, Bacteroidetes and Proteobacteria were hosts of more diverse resistance genes (four antimicrobials each).

Table 4. Aminoglycoside, beta-lactam, sulfonamide, phenicol, lincosamide, and erythromycin resistance determinants hosted by microbiota of digital dermatitis lesions for 40 clusters with $\geq 80 \%$ complete genome; resistance genes are in parentheses.

\begin{tabular}{|c|c|c|c|c|c|c|}
\hline Bacterial Taxa & $\begin{array}{l}\text { Aminoglycoside } \\
\text { (aadA1, ant3, ant4, } \\
\text { ant6, aph3, aph6) }\end{array}$ & $\begin{array}{c}\text { Beta-Lactam } \\
\text { (blaOXA, } \\
\text { blaCARB) }\end{array}$ & $\begin{array}{l}\text { Sulfonamide } \\
\text { (sul1, sul2) }\end{array}$ & $\begin{array}{c}\text { Phenicol } \\
\text { (cmx } \mathrm{AB}, \text { flo })\end{array}$ & $\begin{array}{l}\text { Lincosamide } \\
(\ln u \mathrm{~B}, l s a)\end{array}$ & $\begin{array}{c}\text { Erythromycin (erm } \mathrm{A}, \\
\text { erm } \mathrm{B}, \text { erm } \mathrm{F}, \text { erm } \mathrm{X}, \\
\text { myrA) }\end{array}$ \\
\hline Bacteroidetes & 8 & 0 & 3 & 0 & 1 & 4 \\
\hline Porphyromonas somerae & 0 & 0 & 3 & 0 & 0 & 0 \\
\hline Porphyromonas levii & 3 & 0 & 0 & 0 & 0 & 1 \\
\hline Porphyromonadaceae & 0 & 0 & 0 & 0 & 1 & 1 \\
\hline Bacteroidetes & 5 & 0 & 0 & 0 & 0 & 2 \\
\hline Spirochaetes & 85 & 0 & 0 & 0 & 0 & 0 \\
\hline Treponema phagedenis & 1 & 0 & 0 & 0 & 0 & 0 \\
\hline Treponema medium & 9 & 0 & 0 & 0 & 0 & 0 \\
\hline Spirochaetaceae & 75 & 0 & 0 & 0 & 0 & 0 \\
\hline Firmicutes & 9 & 0 & 0 & 0 & 28 & 2 \\
\hline Streptococcus henryi & 3 & 0 & 0 & 0 & 10 & 0 \\
\hline Lactobacillales & 1 & 0 & 0 & 0 & 5 & 0 \\
\hline Clostridiales & 5 & 0 & 0 & 0 & 13 & 2 \\
\hline Tenericutes & 0 & 0 & 0 & 0 & 0 & 0 \\
\hline Mycoplasma fermentans & 0 & 0 & 0 & 0 & 0 & 0 \\
\hline Mycoplasma & 0 & 0 & 0 & 0 & 0 & 0 \\
\hline Proteobacteria & 11 & 1 & 1 & 1 & 0 & 0 \\
\hline Betaproteobacteria & 6 & 1 & 1 & 0 & 0 & 0 \\
\hline Gammaproteobacteria & 5 & 0 & 0 & 1 & 0 & 0 \\
\hline $\begin{array}{l}\text { Total Resistance Genes in the Sample } \\
\text { ( } n=308 \text { clusters) }\end{array}$ & 463 & 36 & 39 & 20 & 153 & 63 \\
\hline
\end{tabular}

\section{Discussion}

Lameness in cows caused by DD poses great challenges to dairy and beef farms across the world. As DD is a complex polymicrobial disease with many of the putative bacterial etiologies requiring fastidious growth conditions, the study of antimicrobial resistance associated with the disease is challenging. Published work characterizing the antimicrobial resistance status of the bacteria involved in the pathogenesis of DD is limited. This study, therefore, was designed to fill this research gap using the novel ProxiMeta Hi-C method that has the capability of identifying specific ARGs within their respective bacterial reservoirs directly from complex microbial communities. In the present study, we identified five phyla carrying multiple genes conferring resistance to tetracyclines and other antimicrobials.

Bacteroidetes, Spirochaetes, and Firmicutes were the most abundant phyla in the samples that we analyzed, which is in agreement with previous studies $[14,19,21]$. In this study, the lower-level classification of bacteria revealed the presence of Pophyromonadaceae, Treponema, Clostridiales, Mycoplasma, and Lactobacillales, which is also consistent with previous reports $[5,14]$. However, variations in the diversity and frequency of bacterial taxa among studies can be expected as the types of bacterial species involved in DD cases vary with the stage of the disease and the lesion sites [41]. For example, in the early stage of the lesions, Bacteroides, Firmicutes (Peptostreptococcus, Peptococcus, Clostridium), and Fusobac- 
terium species are most abundant [42], while the later stages are dominated by Treponema species that appear in low relative abundance in the early stages $[5,14,26]$. Species of Firmicutes are the most significant and diverse bacteria associated with superficial and intermediate zones of the lesions, while Treponema species dominate the deeper layers of the lesions [5,26]. In the present study, samples were collected from representative lesions balanced for each stage (Iowa State University [ISU] DD Scores 1 to 4 ) at a slaughterhouse and macerated together.

Here, the 16S rRNA BLAST analysis and the phylogenetic analysis were used to identify and classify bacterial taxa at the kingdom, class, order, and family levels using the CheckM tool. For example, 6 of the 40 clusters were not classified beyond the kingdom (i.e., Bacteria); however, sequence comparisons of their 16S rRNA sequences by BLAST showed that they have a close match with species of Spirochaetes and Bacteroidetes, along with Erysiplothrix rhusiopathiae. The involvement of the former two taxa in DD pathogenesis has been reported, while the role of the latter taxon is not yet known [5]. Similarly, one of the Spirochaetes clusters has a $97.23 \%$ identity match with T. refringens, which is in agreement with the findings of Nielsen and colleagues [18], where T. refringens-like species along with T. phagedenis-like species were the most abundant Treponema species in DD lesions. In the phylogenetic tree, the Spirochaetes clusters have shown some grouping patterns; clusters $1,2,10,15$, and 28 were clustered around T. denticola ATCC 33520, while cluster 18 was grouped around T. medium ATCC 700293 and T. vincentii F0403. In summary, the Spirochaetes species identified in this study were T. phagedenis, T. medium, T. denticola-like species, and T. medium-/T. vincentii-like species, which is consistent with previous studies $[5,18,22,24]$.

We also found numerous tetracycline resistance genes in the DD samples. Typically, various treatment regimens of tetracyclines have been reported to result in a clinical improvement of DD in dairy cattle $[29,43,44]$. Previously, low efficacy of oxytetracycline treatment was observed in dairy cows with DD, which suggested possible antibiotic resistance development [30]. In the current study, we identified 16 classes of tetracycline resistance determinants encoding ribosomal protection proteins, efflux pumps, and enzymatic inactivation.

This study shows that tetracycline resistance genes are found in high abundance in the DD lesions, as demonstrated by the detection of large numbers of the core tetracycline resistome, such as tet $Q$, tet $O$, tet $M$, and tet $W$. Previously tet $A$, tet $M$, tet $O$, tet $Q$, tet $W$, tet $X$, and tet $Y$ were detected in cattle excrement, manure, and soil on dairy farms [45]. Compared with the current study, these genes, except for tet $A$ and tet $Y$, were detected in DD samples. Furthermore, we discovered two more gene types, tetL (four hits) and tet $Z$ (six hits). All tetracycline resistance determinants detected here were reported previously from dairy farms and agricultural environments [45-47]. However, through the use of metagenomic $\mathrm{Hi}-\mathrm{C}$, we were able to report for the first time the presence of tetracycline resistance genes in a sample obtained from DD cases. This is particularly important for the specific fastidious bacteria involved in the pathogenesis of this disease. Since many of these bacteria grow poorly, or not at all, on artificial media, characterizing the emergence of antibiotic resistance among them using conventional methods is not possible [5]. However, using the Hi-C method enabled us to identify ARG hosting specific bacterial taxa [40].

In the present study, tet $Q$ was the most prevalent and had the largest bacterial taxa distribution, in contrast to a previous study where tet $M$ was the most abundant gene [47]. The discrepancy might be due to the difference in sample types; we used macerated biopsies of DD lesions, whereas Kobash et al. (2007) used swine and poultry feces. In general, this study demonstrates the widespread distribution of tetracycline resistance genes in the microbiota of DD lesions.

The ribosomal protection protein-encoding genes were also found to be most dominant, agreeing with a previous report [48]. However, some studies documented efflux pump genes as dominant [46,49]. Previously, 28 distinct classes of genes encoding the efflux pumps and 12 distinct classes encoding ribosome protection proteins were reported [46]. Some of the ribosomal protection protein-encoding genes, such as tet $M$ and tet $W$, are 
associated with conjugative transposons and their host range has increased dramatically in recent years [46]. Besides that, similar to our findings, tet $X$ and tet 37 that encode less prevalent resistance mechanisms such as monooxygenases and mutations within the $16 \mathrm{~S}$ rRNA were reported [49]. In the present study, we detected tetX in Firmicutes. On the other hand, two of the identified bacterial taxa were found to carry tet 31 , and one bacterial taxon carried tet33, also consistent with a previous study [46]. tet31 and tet33 confer resistance by inducing the efflux pump mechanism.

Bacteroidetes species were found to host the largest number of tetracycline resistance genes $(n=445)$ compared to other phyla with similar relative abundance. Except for one gene (encoding for the efflux pump), the rest of these genes were ribosomal protection protein-encoding genes. The increase in the carriage of tetracycline resistance genes, such as tetQ, by this phylum, was previously noted [50-52]. In agreement with the present study, tet $\mathrm{M}$ and tet $\mathrm{W}$ was isolated from Porphyromonadaceae, a family in this phylum [46]. Horizontal transfer of tetracycline resistance genes among Bacteroides species and between Bacteroides species that colonize humans and livestock were also documented $[53,54]$. Conjugative transposons and plasmids play a significant role in the horizontal transfer of these resistance genes among Bacteroides species and in the increase of tetracycline resistance among them [54,55]. Although antimicrobial resistance studies related to livestock isolates are absent, studies in human isolates suggest that horizontal transfer of resistance genes mainly contributes to the high carriage of ARGs in Bacteroidetes.

Firmicutes hosted 146 tetracycline resistance genes classified into seven types of genes that, except for one, encoded ribosomal protection genes. Firmicutes was unique from other phyla in that it was the only phylum that carried the tet $X$ gene encoding the inactivation enzyme. This gene confers resistance to all clinically important tetracycline drugs, including tigecycline, a broad-spectrum and last-resort antibiotic for multidrug-resistant pathogens [56]. Among the three bacterial taxa identified in Firmicutes, Clostridiales carried 143 tetracycline resistance genes. Like the present study, tet $\mathrm{M}$ was reported from Lactobacillales and Clostridiales from dairy farms in the Czech Republic [45], tetW from Clostridiales and Lactobacillales, and tet32 from Clostridiales [46]. Firmicutes species are among the most abundant bacterial taxa in DD lesions [14,19].

Spirochaetes were found to carry 94 tetracycline resistance genes, representing 5 classes of ribosomal protection genes. Spirochete treponemes are the most predominant microorganisms identified in DD lesions of cattle $[5,19,20,24]$. However, studies of antimicrobial resistance status of Treponema isolates are lacking, particularly for DD cases. Human isolates of Treponema species, such as T. denticola [57] and Treponema pallidum [58], have been found to carry tetracycline resistance genes. tet $B$ was detected in oral Treponema isolates obtained from a human periodontal patient [57]. Significant genetic relatedness between oral Treponema isolates from humans and Treponema isolates from DD in cattle has been reported [5].

Tenericutes was found to host only one tetracycline resistance gene, tet $M$, which encodes ribosomal protection proteins. There is no report on the tetracycline resistance status of Mycoplasma isolates from DD lesions. However, other tetracycline-resistant Mycoplasma isolates from cattle and humans have been described [59-61]. The emergence of tetracycline resistance in Mycoplasma species was attributed to tetM acquisition [59].

Proteobacteria hosted three tet 31 genes encoding the efflux pump and one tetW gene encoding ribosomal protection proteins. The role of Proteobacteria species in the pathogenesis of DD is not well understood, but they are more abundant in DD lesions than healthy skin $[9,19]$. However, if these antimicrobial determinants are carried by mobile genetic elements such as plasmids, Proteobacteria species might transfer these genes to other pathogenic bacteria, even if they play no role in the disease process.

We also observed the co-occurrence of other antimicrobial resistance genes conferring resistance to aminoglycosides, beta-lactams, sulfonamides, phenicol, lincosamides, and erythromycins in the sample. Some of these antimicrobials are used for the treatment of DD: penicillin (beta-lactams) systematically, lincomycin/spectinomycin (lincosamide) and chlo- 
ramphenicol (phenicol in the UK, but illegal in the USA) topically, and erythromycin and lincomycin/spectinomycin in foot baths [62]. The rest of them are used for the treatment of different diseases on dairy farms $[63,64]$. The detection of resistance genes against these antimicrobials in the DD lesions has not been reported thus far; however, their existence in samples from livestock, livestock products, and farm environments has been documented [65-67]. Similarly, the antimicrobial susceptibility test of Treponema phagedenis-like spirochetes isolated from dairy cattle with DD lesions in Japan showed that oxytetracycline, lincomycin, enrofloxacin, chloramphenicol, ceftiofur, and gentamicin had intermediate MIC values [31]. In agreement with our findings, genes conferring resistance to multiple antimicrobials such as tetracycline, sulfonamide, quinolone, macrolides (erythromycin), and aminoglycoside were detected in wastewater and surface water samples collected from pig, cattle, and chicken farms in China (Chen et al., 2015). These resistance genes and their bacterial reservoirs can pollute the environment and jeopardize public health $[68,69]$. This warrants concerted efforts among human, animal, and environmental health key players to slow down the emergence of antimicrobial resistance in general and to mitigate the dissemination of the resistance genes in the environment, in particular. Genes conferring resistance to commonly used footbath heavy metals, such as copper and zinc sulfate, were not detected in this study, which is in contrast to a previous report [19].

\section{Materials and Methods}

\subsection{Description of the Sample}

The sample used in this study was obtained from large pooled samples collected from cows with lesions of DD at slaughterhouses for the purpose of inducing lesions experimentally [70]. The skin lesions were biopsied from cows with DD at various stages. A scoring system that is based on the morphologies of DD lesions and representing various stages of DD progression was previously developed in our lab [14]. Biopsy samples were collected from DD lesions representative of each score. The harvested biopsy materials were placed into Induction Broth, and then combined and macerated in an anaerobic chamber as described in our publication [70]. The macerated samples were stored at $-80{ }^{\circ} \mathrm{C}$ in a freezer. For this study, an aliquot of inoculum was thawed at room temperature for DNA extraction and laboratory preparation according to the protocols of Phase Genomics and ZymoBiomics.

\subsection{DNA Extraction and Library Preparation}

\subsubsection{DNA Extraction for Shotgun Metagenomics}

DNA was extracted from the sample according to ZymoBIOMICS instructions. Briefly, the sample was thawed at room temperature for $30 \mathrm{~min}$. A $100 \mathrm{mg}$ sample was transferred to a $2 \mathrm{~mL}$ ZR BashingBead lysis tube and mixed with $250 \mu \mathrm{L}$ deionized sterile water, $750 \mu \mathrm{L}$ lysis solution, and $50 \mu \mathrm{L}$ proteinase $\mathrm{K}$. The samples were processed by a bead beater for $10 \mathrm{~min}$ followed by incubation for at least $30 \mathrm{~min}$ in a water bath at $55^{\circ} \mathrm{C}$. Then, the lysis tubes were centrifuged in a microcentrifuge at $10,000 \times g$ for $3 \mathrm{~min}$. The supernatant was harvested to columns and then washed with DNA Wash Buffer 1 and 2. The final product was eluted with $75 \mu \mathrm{L}$ DNase/RNase-free water. The concentration of eluted DNA was measured first by NanoDrop 3300 Fluorospectrometer and confirmed by the Qubit Fluorometer. The whole-genome extracts were submitted to the DNA Facility of Iowa State University, where a single flow cell lane Illumina HiSeq platform was used for sequencing $(2 \times 150$ base pairs).

\subsubsection{DNA Extraction and Library Preparation for ProxiMeta Hi-C Metagenomics}

We used a Phase Genomics (Seattle, WA, USA) ProxiMeta Hi-C Microbiome Kit, which is a commercially available version of the Hi-C protocol, for DNA extraction and library preparation. Briefly, $100 \mathrm{mg}$ of the same sample used in the shotgun procedures was washed with Tris-buffered saline (TBS), followed by in vivo crosslinking of genetic materials (both chromosomal and non-chromosomal) using a formaldehyde solution, 
while the bacterial cells were still intact. Subsequently, it was digested using the Sau3AI and MlucI restriction enzymes and proximity ligated with biotinylated nucleotides to create chimeric molecules composed of fragments from different regions of genomes that were physically proximal in vivo according to the manufacturer's instructions for the kit. The chance of inter-cellular interactions of genetic materials is negligible. Following the protocol, molecules were pulled down with streptavidin beads and processed into an Illumina-compatible sequencing library. Sequencing was performed on an Illumina HiSeq instrument $(2 \times 150$ base pairs) at the DNA Facility of Iowa State University.

\subsubsection{Metagenomic Data Analysis}

Shotgun and Hi-C metagenomic sequencing files were uploaded to the Phase Genomics cloud-based bioinformatics portal for subsequent analysis. Shotgun reads were filtered and trimmed for quality using fastp [71] and then assembled with MEGAHIT [72,73] using default options. Following the instructions of the kit, Hi-C reads were aligned to the assembly (https:/ / phasegenomics.github.io/2019/09/19/hic-alignment-and-qc.html (accessed on 22 February 2021)). Briefly, reads were aligned using BWA-MEM [74] with the $-5 S P$ and $-t 8$ options specified, and all other options default. SAMBLASTER [75] was used to flag PCR duplicates, which were later excluded from the analysis. Alignments were then filtered with samtools [76] using the -F 2304 filtering flag to remove non-primary and secondary alignments. Metagenome deconvolution was performed with ProxiMeta [37,38]. Clusters were assessed for quality using CheckM [77] and assigned preliminary taxonomic classifications with Mash [78]. Identification of ARGs was conducted by aligning assembled contigs to curated ARGs of the MEGARes database using minimap2 [79]. Hi-C data were then used to link identified ARG sequences to host genomes and genome fragments within ProxiMeta by counting the number of $\mathrm{Hi}-\mathrm{C}$ reads linking such sequences to putative hosts $[36,40]$.

\section{3. $16 S$ rRNA BLASTing and Phylogenetic Tree Plotting}

From the metagenomics, we obtained 40 bacterial clusters (taxa) with $\geq 80 \%$ complete genome. The clusters were annotated using the PATRIC online tool (www.patricbrc.org (accessed on 22 February 2021)) to search for the best matching bacterial species for those clusters whose 16S rRNA gene was assembled from the metagenome data. The $16 \mathrm{~S}$ rRNA sequence was blasted on the website of the U.S. National Center for Biotechnology Information (https:/ / www.ncbi.nlm.nih.gov/ (accessed on 22 February 2021)). Similarly, PATRIC online tool was used to plot the phylogenetic trees of the clusters; previously reported bacterial isolates from DD and other references had been used as reference organisms on the dendrogram.

\section{Conclusions}

The inclusion of a DNA crosslinking step before DNA extraction and subsequent proximity ligation in the $\mathrm{Hi}-\mathrm{C}$ metagenomics enabled individual microbial genomes to be deconvoluted from within metagenomic DNA samples. Thus, antimicrobial resistance genes were identified and assigned to their taxonomic sources. Our study shows that tetracycline resistance genes are widely distributed in bacteria that are believed to be involved in the pathogenesis of DD. Similarly, we identified the co-occurrence of resistance determinants to other commonly used antimicrobials with their respective bacterial hosts, which demonstrates the superiority of the Hi-C approach over other metagenomic methods in tracking ARGs in a complex microbial community. To our knowledge, this is the first study that provides genetic evidence of resistance to tetracycline and other antimicrobials harbored by bacteria that are involved in the pathogenesis of DD. The clinical importance of these findings is doubtless, but its interpretation requires precaution. Furthermore, the high abundance and diversity of tetracycline resistance genes, the most common antibiotic used for the treatment of $\mathrm{DD}$, in the sequenced sample may provide insights into the incomplete resolution of many DD lesions following aggressive treatment with 
tetracyclines. Future efforts will use the Hi-C metagenomic approach to substantiate the role of horizontal gene transfer in the dissemination of antimicrobial determinants on farms as well as environments.

Supplementary Materials: The following are available online at https:/ /www.mdpi.com/2079-6 382/10/2/221/s1: Table S1: Forty bacterial taxa with $\geq 80 \%$ complete genomes detected in digital dermatitis lesions in cattle. Table S2: Tetracycline resistance gene distribution in 40 bacterial taxa with $\geq 80 \%$ complete genomes detected in digital dermatitis lesions in cattle.

Author Contributions: Conceptualization, P.J.P., G.J.P. and A.F.B.; methodology, A.F.B., P.J.P., G.J.P. and A.H.; formal analysis, A.F.B. and P.J.P.; investigation, A.F.B. and A.H.; resources, P.J.P.; data curation, A.F.B.; writing—original draft preparation, A.F.B.; writing—review and editing, A.F.B., P.J.P., G.J.P. and A.H.; visualization, A.F.B.; supervision, P.J.P.; project administration, A.F.B., P.J.P. and A.H.; funding acquisition, P.J.P. All authors have read and agreed to the published version of the manuscript.

Funding: This research was funded by the Agriculture and Food Research Initiative's Competitive Grant 2017-68003-26499 from the USDA National Institute of Food and Agriculture. An additional fund was obtained from the Iowa State University Antimicrobial Resistance Consortium. The development of ProxiMeta and affiliated host-attribution algorithms were supported in part by grants R44AI122654 and R44AI150008 from NIAID and OPP1195084 from the Bill and Melinda Gates Foundation to Phase Genomics, Inc.

Institutional Review Board Statement: Not applicable.

Informed Consent Statement: Not applicable.

Data Availability Statement: Metagenomic shotgun and Hi-C sequence data are available at SRA accession PRJNA704056. Processed data for linking contigs to genome clusters using Hi-C data are available at https:/ / osf.io/4wnh2/ (accessed on 22 February 2021).

Acknowledgments: Ivan Liachko and Max Press from Phase Genomics provided helpful advice.

Conflicts of Interest: The authors declare no conflict of interest.

\section{References}

1. van de Gucht, T.; Saeys, W.; van Meensel, J.; van Nuffel, A.; Vangeyte, J.; Lauwers, L. Farm-specific economic value of automatic lameness detection systems in dairy cattle: From concepts to operational simulations. J. Dairy Sci. 2018, 101, 637-648. [CrossRef] [PubMed]

2. Relun, A.; Lehebel, A.; Chesnin, A.; Guatteo, R.; Bareille, N. Association between digital dermatitis lesions and test-day milk yield of Holstein cows from 41 French dairy farms. J. Dairy Sci. 2013, 96, 2190-2200. [CrossRef] [PubMed]

3. Terrell, S.P.; Reinhardt, C.D.; Larson, C.K.; Vahl, C.I.; Thomson, D.U. Incidence of lameness and association of cause and severity of lameness on the outcome for cattle on six commercial beef feedlots. J. Am. Vet. Med. Assoc. 2017, 250, 437-445. [CrossRef]

4. Sullivan, L.E.; Carter, S.D.; Blowey, R.; Duncan, J.S.; Grove-White, D.; Evans, N.J. Digital dermatitis in beef cattle. Vet. Rec. 2013, 173, 582. [CrossRef] [PubMed]

5. Wilson-Welder, J.H.; Alt, D.P.; Nally, J.E. The etiology of digital dermatitis in ruminants: Recent perspectives. Vet. Med.-Res. Rep. 2015, 6, 155-164.

6. Plummer, P.J.; Krull, A. Clinical Perspectives of Digital Dermatitis in Dairy and Beef Cattle. Vet. Clin. N. Am.-Food A 2017, 33, 165-181. [CrossRef] [PubMed]

7. Cartwright, S.L.; Malchiodi, F.; Thompson-Crispi, K.; Miglior, F.; Mallard, B.A. Short communication: Prevalence of digital dermatitis in Canadian dairy cattle classified as high, average, or low antibody and cell-mediated immune responders. J. Dairy Sci. 2017, 100, 8409-8413. [CrossRef] [PubMed]

8. Holzhauer, M.; Hardenberg, C.; Bartels, C.J.M.; Frankena, K. Herd- and cow-level prevalence of digital dermatitis in the Netherlands and associated factors. J. Dairy Sci. 2006, 89, 580-588. [CrossRef]

9. Hesseling, J.; Legione, A.R.; Stevenson, M.A.; McCowan, C.I.; Pyman, M.F.; Finochio, C.; Nguyen, D.; Roic, C.L.; Thiris, O.L.; Zhang, A.J.; et al. Bovine digital dermatitis in Victoria, Australia. Aust. Vet. J. 2019, 97, 404-413. [CrossRef]

10. Read, D.H.; Walker, R.L. Papillomatous digital dermatitis (footwarts) in California dairy cattle: Clinical and gross pathologic findings. J. Vet. Diagn. Invest. 1998, 10, 67-76. [CrossRef]

11. van Amstel, S.R.; van Vuuren, S.; Tutt, C.L.C. Digital dermatitis - report of an outbreak. J. S. Afr. Vet. Assoc. 1995, 66, 177-181.

12. Cha, E.; Hertl, J.A.; Bar, D.; Grohn, Y.T. The cost of different types of lameness in dairy cows calculated by dynamic programming. Prev. Vet. Med. 2010, 97, 1-8. [CrossRef] 
13. Refaai, W.; Van Aert, M.; Abd El-Aal, A.M.; Behery, A.E.; Opsomer, G. Infectious diseases causing lameness in cattle with a main emphasis on digital dermatitis (Mortellaro disease). Livest. Sci. 2013, 156, 53-63. [CrossRef]

14. Krull, A.C.; Shearer, J.K.; Gorden, P.J.; Cooper, V.L.; Phillips, G.J.; Plummer, P.J. Deep Sequencing Analysis Reveals Temporal Microbiota Changes Associated with Development of Bovine Digital Dermatitis. Infect. Immun. 2014, 82, 3359-3373. [CrossRef]

15. Trott, D.J.; Moeller, M.R.; Zuerner, R.L.; Goff, J.P.; Waters, W.R.; Alt, D.P.; Walker, R.L.; Wannemuehler, M.J. Characterization of Treponema phagedenis-like spirochetes isolated from papillomatous digital dermatitis lesions in dairy cattle. J. Clin. Microbiol. 2003, 41, 2522-2529. [CrossRef]

16. Rebhun, W.C.; Payne, R.M.; King, J.M.; Wolfe, M.; Begg, S.N. Interdigital papillomatosis in dairy-cattle. J. Am. Vet. Med. Assoc. 1980, 177, 437-440. [PubMed]

17. Rebhun, W.C. Interdigital papillomatosis in dairy cattle. Proc. XIIth World Congress Diseases Cattle Neth. 1982, II, $833-837$.

18. Nielsen, M.W.; Strube, M.L.; Isbrand, A.; Al-Medrasi, W.D.H.M.; Boye, M.; Jensen, T.K.; Klitgaard, K. Potential bacterial core species associated with digital dermatitis in cattle herds identified by molecular profiling of interdigital skin samples. Vet. Microbiol. 2016, 186, 139-149. [CrossRef]

19. Zinicola, M.; Higgins, H.; Lima, S.; Machado, V.; Guard, C.; Bicalho, R. Shotgun Metagenomic Sequencing Reveals Functional Genes and Microbiome Associated with Bovine Digital Dermatitis. PLoS ONE 2015, 10, e0133674. [CrossRef] [PubMed]

20. Klitgaard, K.; Boye, M.; Capion, N.; Jensen, T.K. Evidence of multiple Treponema phylotypes involved in bovine digital dermatitis as shown by 16S rRNA gene analysis and fluorescence in situ hybridization. J. Clin. Microbiol. 2008, 46, 3012-3020. [CrossRef]

21. Yano, T.; Moe, K.K.; Yamazaki, K.; Ooka, T.; Hayashi, T.; Misawa, N. Identification of candidate pathogens of papillomatous digital dermatitis in dairy cattle from quantitative 16S rRNA clonal analysis. Vet. Microbiol. 2010, 143, 352-362. [CrossRef]

22. Evans, N.J.; Brown, J.M.; Demirkan, I.; Singh, P.; Getty, B.; Timofte, D.; Vink, W.D.; Murray, R.D.; Blowey, R.W.; Birtles, R.J.; et al. Association of unique, isolated treponemes with bovine digital dermatitis lesions. J. Clin. Microbiol. 2009, 47, 689-696. [CrossRef] [PubMed]

23. Zinicola, M.; Lima, F.; Lima, S.; Machado, V.; Gomez, M.; Doepfer, D.; Guard, C.; Bicalho, R. Altered microbiomes in bovine digital dermatitis lesions, and the gut as a pathogen reservoir. PLoS ONE 2015, 10, e0120504. [CrossRef]

24. Mamuad, L.L.; Seo, B.J.; Al Faruk, M.S.; Espiritu, H.M.; Jin, S.J.; Kim, W.-I.; Lee, S.-S.; Cho, Y.-I. Treponema spp., the dominant pathogen in the lesion of bovine digital dermatitis and its characterization in dairy cattle. Vet. Microbiol. 2020, 245, 108696. [CrossRef]

25. Espiritu, H.M.; Mamuad, L.L.; Jin, S.-j.; Kim, S.-h.; Kwon, S.-w.; Lee, S.-s.; Lee, S.-m.; Cho, Y.-i. Genotypic and phenotypic characterization of Treponema phagedenis from bovine digital dermatitis. Microorganisms 2020, 8, 1520. [CrossRef] [PubMed]

26. Santos, T.M.A.; Pereira, R.V.; Caixeta, L.S.; Guard, C.L.; Bicalho, R.C. Microbial diversity in bovine papillomatous digital dermatitis in Holstein dairy cows from upstate New York. Fems Microbiol. Ecol. 2012, 79, 518-529. [CrossRef] [PubMed]

27. Beninger, C.; Naqvi, S.A.; Naushad, S.; Orsel, K.; Luby, C.; Derakhshani, H.; Khafipour, E.; De Buck, J. Associations between digital dermatitis lesion grades in dairy cattle and the quantities of four Treponema species. Vet. Res. 2018, 49, 1-15. [CrossRef] [PubMed]

28. Manske, T.; Hultgren, J.; Bergsten, C. Topical treatment of digital dermatitis associated with severe heel-horn erosion in a Swedish dairy herd. Prev. Vet. Med. 2002, 53, 215-231. [CrossRef]

29. Watts, K.M.; Lahiri, P.; Arrazuria, R.; De Buck, J.; Knight, C.G.; Orsel, K.; Barkema, H.W.; Cobo, E.R. Oxytetracycline reduces inflammation and Treponeme burden whereas vitamin D-3 promotes beta-defensin expression in bovine infectious digital dermatitis. Cell Tissue Res. 2020, 379, 337-348. [CrossRef]

30. Shearer, J.K.; Hernandez, J. Efficacy of two modified nonantibiotic formulations (Victory) for treatment of papillomatous digital dermatitis in dairy cows. J. Dairy Sci. 2000, 83, 741-745. [CrossRef]

31. Yano, T.; Moe, K.K.; Chuma, T.; Misawa, N. Antimicrobial susceptibility of Treponema phagedenis-like spirochetes isolated from dairy cattle with papillomatous digital dermatitis lesions in Japan. J. Vet. Med. Sci. 2010, 72, 379-382. [CrossRef]

32. Roberts, M.C. Tetracycline resistance determinants: Mechanisms of action, regulation of expression, genetic mobility, and distribution. Fems Microbiol. Rev. 1996, 19, 1-24. [CrossRef] [PubMed]

33. Tang, K.L.; Caffrey, N.P.; Nobrega, D.B.; Cork, S.C.; Ronksley, P.E.; Barkema, H.W.; Polachek, A.J.; Ganshorn, H.; Sharma, N.; Kellner, J.D.; et al. Restricting the use of antibiotics in food-producing animals and its associations with antibiotic resistance in food-producing animals and human beings: A systematic review and meta-analysis. Lancet Planet Hlth. 2017, 1, e316-e327. [CrossRef]

34. Evans, N.J.; Brown, J.M.; Demirkan, I.; Birtles, R.; Hart, C.A.; Carter, S.D. In vitro susceptibility of bovine digital dermatitis associated spirochaetes to antimicrobial agents. Vet. Microbiol. 2009, 136, 115-120. [CrossRef]

35. Schmieder, R.; Edwards, R. Insights into antibiotic resistance through metagenomic approaches. Future Microbiol. 2012, 7, 73-89. [CrossRef] [PubMed]

36. Bickhart, D.; Watson, M.; Koren, S.; Panke-Buisse, K.; Cersosimo, L.M.; Press, M.O.; Van Tassell, C.P.; Van Kessel, J.A.S.; Haley, B.J.; Kim, S.W.; et al. Assignment of virus and antimicrobial resistance genes to microbial hosts in a complex microbial community by combined long-read assembly and proximity ligation. Genome Biol. 2019, 20, 153. [CrossRef] [PubMed]

37. Press, M.O.; Wiser, A.H.; Kronenberg, Z.N.; Langford, K.W.; Shakya, M.; Lo, C.C.; Liachko, I. Hi-C deconvolution of a human gut microbiome yields high-quality draft genomes and reveals plasmid-genome interactions. BioRxiv 2017. [CrossRef] 
38. Stewart, R.D.; Auffret, M.D.; Warr, A.; Wiser, A.H.; Press, M.O.; Langford, K.W.; Liachko, I.; Snelling, T.J.; Dewhurst, R.J.; Walker, A.W.; et al. Assembly of 913 microbial genomes from metagenomic sequencing of the cow rumen. Nat. Commun. 2018, 9, 1-11. [CrossRef]

39. Burton, J.N.; Liachko, I.; Dunham, M.J.; Shendure, J. Species-Level Deconvolution of Metagenome Assemblies with Hi-C-Based Contact Probability Maps. G3 (Bethesda) 2014, 4, 1339-1346. [CrossRef]

40. Stalder, T.; Press, M.O.; Sullivan, S.; Liachko, I.; Top, E.M. Linking the resistome and plasmidome to the microbiome. ISME J. 2019, 13, 2437-2446. [CrossRef]

41. Staton, G.J.; Sullivan, L.E.; Blowey, R.W.; Carter, S.D.; Evans, N.J. Surveying bovine digital dermatitis and non-healing bovine foot lesions for the presence of Fusobacterium necrophorum, Porphyromonas endodontalis and Treponema pallidum. Vet. Rec. 2020, 186, 450. [CrossRef]

42. Koniarova, I.; Orsag, A.; Ledecky, V. The role of anaerobe in the occurrence of dermatitis digitalis-et-interdigitalis in cattle. Vet. Med.-Czech. 1993, 38, 589-596.

43. Jacobs, C.; Orsel, K.; Mason, S.; Barkema, H.W. Comparison of effects of routine topical treatments in the milking parlor on digital dermatitis lesions. J. Dairy Sci. 2018, 101, 5255-5266. [CrossRef]

44. Cutler, J.H.H.; Cramer, G.; Walter, J.J.; Millman, S.T.; Kelton, D.F. Randomized clinical trial of tetracycline hydrochloride bandage and paste treatments for resolution of lesions and pain associated with digital dermatitis in dairy cattle. J. Dairy Sci. 2013, 96, 7550-7557. [CrossRef]

45. Kyselkova, M.; Jirout, J.; Vrchotova, N.; Schmitt, H.; Elhottova, D. Spread of tetracycline resistance genes at a conventional dairy farm. Front. Microbiol. 2015, 6, 536. [CrossRef] [PubMed]

46. Roberts, M.C. Update on acquired tetracycline resistance genes. Fems Microbiol. Lett. 2005, 245, 195-203. [CrossRef] [PubMed]

47. Kobashi, Y.; Hasebe, A.; Nishio, M.; Uchiyama, H. Diversity of tetracycline resistance genes in bacteria isolated from various agricultural environments. Microbes Environ. 2007, 22, 44-51. [CrossRef]

48. Cheng, W.X.; Chen, H.; Su, C.; Yan, S.H. Abundance and persistence of antibiotic resistance genes in livestock farms: A comprehensive investigation in eastern China. Environ. Int. 2013, 61, 1-7. [CrossRef]

49. Fabian, N.; Starosta, A.L.; Arenz, S.; Sohmen, D.; Doenhoefer, A.; Wilson, D.N. Tetracycline antibiotics and resistance mechanisms. Biol. Chem. 2014, 395, 559-575.

50. Shoemaker, N.B.; Vlamakis, H.; Hayes, K.; Salyers, A.A. Evidence for extensive resistance gene transfer among Bacteroides spp. and among Bacteroides and other genera in the human colon. Appl. Environ. Microbiol. 2001, 67, 561-568. [CrossRef]

51. Nikolich, M.P.; Shoemaker, N.B.; Salyers, A.A. A Bacteroides tetracycline resistance gene represents a new class of ribosome protection tetracycline resistance. Antimicrob. Agents Chemother. 1992, 36, 1005-1012. [CrossRef]

52. Speer, B.S.; Bedzyk, L.; Salyers, A.A. Evidence that a novel tetracycline resistance gene found on 2 Bacteroides transposons encodes an NADP-requiring oxidoreductase. J. Bacteriol. 1991, 173, 176-183. [CrossRef]

53. Nikolich, M.P.; Hong, G.; Shoemaker, N.B.; Salyers, A.A. Evidence for natural horizontal transfer of tetQ between bacteria that normally colonize humans and bacteria that normally colonize livestock. Appl. Environ. Microb. 1994, 60, 3255-3260. [CrossRef] [PubMed]

54. Whittle, G.; Shoemaker, N.B.; Salyers, A.A. The role of Bacteroides conjugative transposons in the dissemination of antibiotic resistance genes. Cell. Mol. Life Sci. 2002, 59, 2044-2054. [CrossRef] [PubMed]

55. Quesada-Gomez, C. Bacteroides mobilizable and conjugative genetic elements: Antibiotic resistance among clinical isolates. Rev. Esp. Quim. 2011, 24, 184-190.

56. Volkers, G.; Palm, G.J.; Weiss, M.S.; Wright, G.D.; Hinrichs, W. Structural basis for a new tetracycline resistance mechanism relying on the TetX monooxygenase. Febs Lett. 2011, 585, 1061-1066. [CrossRef] [PubMed]

57. Roberts, M.C.; Chung, W.O.; Roe, D.E. Characterization of tetracycline and erythromycin resistance determinants in Treponema denticola. Antimicrob. Agents Chemother. 1996, 40, 2236. [CrossRef] [PubMed]

58. Stamm, L.V. Global challenge of antibiotic-resistant Treponema pallidum. Antimicrob. Agents Chemother. 2010, 54, 583-589. [CrossRef] [PubMed]

59. Taylor-Robinson, D.; Bebear, C. Antibiotic susceptibilities of mycoplasmas and treatment of mycoplasmal infections. J. Antimicrob. Chemoth. 1997, 40, 622-630. [CrossRef]

60. Gautier-Bouchardon, A.V. Antimicrobial resistance in Mycoplasma spp. Microbiol. Spectrum 2018, 6, ARBA-0030-2018.

61. Siugzdaite, J.; Gabinaitiene, A.; Kerziene, S. Susceptibility of Mycoplasma bovis field isolates to antimicrobial agents. Vet. Med-Czech 2012, 57, 575-582. [CrossRef]

62. Laven, R.A.; Logue, D.N. Treatment strategies for digital dermatitis for the UK. Vet. J. 2006, 171, 79-88. [CrossRef]

63. FDA 2018 Summary Report on Antimicrobials Sold or Distributed for Use in Food-Producing Animals. FDA; 2019. Available online: https: / /www.fda.gov/media/133411/download (accessed on 10 December 2019).

64. Schrag, N.F.D.; Godden, S.M.; Apley, M.D.; Singer, R.S.; Lubbers, B.V. Antimicrobial use quantification in adult dairy cows - Part 3-Use measured by standardized regimens and grams on 29 dairies in the United States. Zoonoses Public Hlth. 2020, 67, 82-93. [CrossRef]

65. Huber, H.; Giezendanner, N.; Stephan, R.; Zweifel, C. Genotypes, antibiotic resistance profiles and microarray-based characterization of methicillin-resistant Staphylococcus aureus strains isolated from livestock and veterinarians in Switzerland. Zoonoses Public Hlth 2011, 58, 343-349. [CrossRef] [PubMed] 
66. Chen, B.A.; Hao, L.J.; Guo, X.Y.; Wang, N.; Ye, B.P. Prevalence of antibiotic resistance genes of wastewater and surface water in livestock farms of Jiangsu province, China. Environ. Sci. Pollut. R. 2015, 22, 13950-13959. [CrossRef] [PubMed]

67. Mu, Q.H.; Li, J.; Sun, Y.X.; Mao, D.Q.; Wang, Q.; Luo, Y. Occurrence of sulfonamide-, tetracycline-, plasmid-mediated quinoloneand macrolide-resistance genes in livestock feedlots in northern China. Environ. Sci. Pollut. R. 2015, 22, 6932-6940. [CrossRef] [PubMed]

68. Wang, N.; Yang, X.H.; Jiao, S.J.; Zhang, J.; Ye, B.P.; Gao, S.X. Sulfonamide-resistant bacteria and their resistance genes in soils fertilized with manures from Jiangsu province, southeastern China. PLoS ONE 2014, 9, e112626. [CrossRef]

69. Pruden, A.; Pei, R.T.; Storteboom, H.; Carlson, K.H. Antibiotic resistance genes as emerging contaminants: Studies in northern Colorado. Env. Sci. Tech. 2006, 40, 7445-7450. [CrossRef]

70. Krull, A.C.; Cooper, V.L.; Coatney, J.W.; Shearer, J.K.; Gorden, P.J.; Plummer, P.J. A highly effective protocol for the rapid and consistent induction of digital dermatitis in Holstein calves. PLoS ONE 2016, 11, e0154481. [CrossRef]

71. Bushnell, B.; Rood, J.; Singer, E. BBMerge - Accurate paired shotgun read merging via overlap. PLoS ONE 2017, 12, e0185056.

72. Li, D.; Liu, C.-M.; Luo, R.; Sadakane, K.; Lam, T.-W. MEGAHIT: An ultra-fast single-node solution for large and complex metagenomics assembly via succinct de Bruijn graph. Bioinformatics 2015, 31, 1674-1676. [CrossRef]

73. Li, D.; Luo, R.; Liu, C.-M.; Leung, C.-M.; Ting, H.-F.; Sadakane, K.; Yamashita, H.; Lam, T.-W. MEGAHIT v1.0: A fast and scalable metagenome assembler driven by advanced methodologies and community practices. Methods 2016, 102, 3-11. [CrossRef]

74. Li, H.; Durbin, R. Fast and accurate long-read alignment with Burrows-Wheeler transform. Bioinformatics 2010, 26, 589-595. [CrossRef]

75. Faust, G.G.; Hall, I.M. SAMBLASTER: Fast duplicate marking and structural variant read extraction. Bioinformatics 2014, 30, 2503-2505. [CrossRef] [PubMed]

76. Li, H.; Handsaker, B.; Wysoker, A.; Fennell, T.; Ruan, J.; Homer, N.; Marth, G.; Abecasis, G.; Durbin, R. 1000 genome project data processing subgroup. The sequence alignment/map format and SAMtools. Bioinformatics 2009, 25, 2078-2079. [CrossRef] [PubMed]

77. Parks, D.H.; Imelfort, M.; Skennerton, C.T.; Hugenholtz, P.; Tyson, G.W. CheckM: Assessing the quality of microbial genomes recovered from isolates, single cells, and metagenomes. Genome Res. 2015, 25, 1043-1055. [CrossRef] [PubMed]

78. Ondov, B.D.; Treangen, T.J.; Melsted, P.; Mallonee, A.B.; Bergman, N.H.; Koren, S.; Phillippy, A.M. Mash: Fast genome and metagenome distance estimation using MinHash. Genome Biol. 2016, 17, 1-14. [CrossRef] [PubMed]

79. Li, H. Minimap2: Pairwise alignment fo r nucleotide sequences. Bioinformatics 2018, 34, 3094-3100. [CrossRef] 